\title{
NOTHING TO AGREE ON: NON-AGREEING SUBJECTS OF COPULAR CLAUSES IN HEBREW
}

\author{
GABI DANON \\ Department of English \\ Bar Ilan University \\ Ramat Gan 52900 \\ Israel \\ Gabi.Danon@biu.ac.il
}

\begin{abstract}
Copular clauses in Hebrew with the copula ze never allow their subjects to agree with the copula or with the post-copular predicate. Following previous work, it is shown that such clauses are not predicational and that their subjects often get a 'hidden event' interpretation. After ruling out an analysis that takes the copula to be the actual subject and an analysis involving a clausal subject, it is argued that these clauses involve a subject that lacks the features needed for subject-external agreement, while having the features needed for subject-internal agreement.
\end{abstract}

Keywords: syntax, semantics, morphology, copula, agreement, Hebrew

\section{Introduction}

\subsection{The empirical problem}

As has often been noted, Modern Hebrew has several different types of copula that differ both in their syntactic properties and in the semantic properties of the clauses in which they appear (see, e.g., Greenberg 2008 for a recent overview). Focusing on so-called pronominal copulas (often referred to in the literature as 'Pron'), we can distinguish two types that are used in present tense verbless clauses:

- hu/hi/hem/hen ('PronH'), which is homophonous to a 3rd person pronoun, and which agrees in number and gender with the subject; this is illustrated in (1) 
- ze/zot/ele ('PronZ'), which is homophonous to a demonstrative or an impersonal pronoun, and which never agrees with the subject; illustrated in (2)

(1) dina hi saxkanit muxšeret.

Dina-F-S PronH-F-S actor-F-S talented-F-S

'Dina is a talented actor.'

(2) ugat gezer ze macxik.

cake-F-S carrot PronZ-M-S funny-M-S

'(Something about) a carrot cake is funny.'

This paper focuses on the syntax and semantics of copular clauses containing the non-agreeing copula PronZ. The two main issues to be addressed are why there is no agreement in this type of clause, and how this relates to the semantics of the clause. It has often been observed that the choice of copula has an effect on interpretation. In the context of PronZ, it was noted by Heller (1999) and Greenberg (2008) that subjects of ze often undergo 'denotation widening' where the predicate applies to an understood eventuality related to the overt subject, rather than to the literal denotation of the subject. For instance, sentence (3) means that something related to little children, such as raising them or dealing with them, is hard work - not that children themselves are hard work:

(3) yeladim ktanim ze avoda kaša.

children-M-P little-M-P ZE-M-S work-F-S hard-F-S

'(Raising/dealing with) little children is hard work.'

This raises several questions. At the purely syntactic level, the question is what is the underlying syntax of non-agreeing ze clauses, and in particular, why can't ze agree with the subject (which is not merely for lack of inflected forms, as feminine and plural forms do exist in the language). From the point of view of the syntax-semantics interface, the question is why the syntax of ze clauses correlates with the observed semantics. An answer to both questions should also provide an explanation for the distribution of non-agreeing subjects, and specifically for the fact that non-agreeing subjects seem to be possible in Hebrew only with $z e$-and not, for instance, with PronH or in clauses containing a verbal predicate. ${ }^{1}$

${ }^{1}$ Additionally, non-agreeing postverbal subjects are allowed in certain cases with unaccusative verbs; these seem to have significantly different properties from subjects of $z e$ and will not be discussed in this paper.

Acta Linguistica Hungarica 59, 2012 
Looking beyond these construction-specific questions, non-agreeing copular clauses also raise some broader theoretical questions. A major unresolved issue in current linguistic theory is the status of what looks like semantic effects of agreement. Under the Agree model of Chomsky (2000; 2001), agreement values and deletes uninterpretable features; hence, by definition, it is impossible for agreement itself, or lack of agreement, to have any kind of semantic effect. Similarly, the model proposed by Bobaljik (2008) argues that agreement is a post-syntactic PF operation; therefore, it cannot have any semantic consequences. Thus, according to these models (among others), what looks like semantic effects of (dis)agreement should follow from some other factor, i.e., in the case of non-agreeing copular clauses there has to be some independent factor that is responsible both for the lack of agreement and for the observed semantic effects.

If there is an independent factor that has an effect on both agreement and semantics, the theoretical challenge is to identify this factor and to show in what way exactly it gives rise to the observed syntactic and semantic effects. Two possible approaches seem to be possible: Either there are structural factors, such as hierarchical relations or locality constraints, which restrict the availability of agreement and which also have an effect on interpretation; or, the entire phenomenon might be reducible to the presence or absence of features on one or more syntactic nodes. In what follows, I will argue for the latter approach; specifically, I will argue that lack of agreement in ze-clauses, as well as the observed semantic effects, are both due to the absence of (interpretable) features on the subject itself. The consequences of this to the analysis of the noun phrase are that it supports making a distinction between the features that participate in DP-internal agreement and those involved in the subject's external agreement (Wechsler-Zlatić 2003; Pereltsvaig 2006).

\section{Preliminaries}

\subsection{Agreeing and non-agreeing copulas}

The two types of copula in Hebrew, PronH and PronZ, display an interesting contrast in their agreement patterns. PronH, on the one hand, must always agree (which follows straightforwardly from the analysis of 
Doron $(1983 ; 1986)$, who claims PronH is an agreement clitic); in the vast majority of cases, it agrees with the subject: ${ }^{2}$

(4) ha-haca'ot šelo hen /*hu ason. the-proposals-F-P his PronH-F-P PronH-M-S disaster-M-S

'His proposals are a disaster.'

PronZ, on the other hand, never agrees with the subject, as shown in (5). It can either bear default features (3rd person singular masculine), in which case it is realized as ze; or, optionally, agree 'to the right', with the predicate, as shown in (6).

(5) *ha-haca'ot šelo ele bdixa.

the-proposals-F-P his ZE-PL joke-F-S

(6) ha-haca'ot šelo ze / zo(t) bdixa.

the-proposals-F-P his ZE-M-S ZE-F-S joke-F-S

'His proposals are a joke.'

Another agreement contrast between PronH and PronZ has to do with the predicate. In $z e$-sentences, as opposed to PronH sentences, an AP predicate never agrees with the subject:

(7) yeladim ze macxik /*macxikim.

children-M-P ZE-M-S funny-M-S funny-M-P

'Something (contextually-determined) involving children is funny.'

(8) yeladim hem macxikim / ${ }^{*}$ macxik.

children-M-P PronH-M-P funny-M-P funny-M-S

'Children are funny.'

Similar facts have been noted in the literature on Scandinavian languages (see, e.g., Hellan 1986; Josefsson 2009), where AP predicates in copular clauses optionally surface with neuter singular agreement, rather than agreeing with the subject; unlike in Hebrew, however, in mainland Scandinavian the contrast between agreeing and non-agreeing APs is not accompanied by any observable contrast on the copula - a fact

${ }^{2}$ As noted by Doron $(1983 ; 1986)$, there are cases where PronH agrees with the predicate; according to Doron, this is possible only when the predicate is a referring expression. These somewhat exceptional cases will not be discussed here. 
which greatly reduces the appeal of an analysis of the Hebrew adjective agreement facts in terms of the lexical properties of the copula.

\subsection{Semantic properties of $z e$-sentences}

Copular clauses with ze differ from those with PronH not only in terms of agreement, but also in their interpretation. This section provides an overview of the semantics of $z e$-clauses, focusing on the claim that they do not express predication.

A central observation in previous work is that $z e$-clauses are semantically distinct from (predicative) PronH clauses. Heller (1999; 2002) argues that pseudoclefts with non-agreeing PronZ are specificational and express identity, whereas those with PronH express predication. Building on Heller's observations, Greenberg (2008) attempts to extend the analysis of PronZ to non-pseudocleft copular sentences and argues that PronZ in general expresses identity (at the type of generalized quantifiers), in contrast with the predicational PronH.

One of the clearest indications that PronZ clauses are interpreted differently from PronH clauses, noted by Heller (1999; 2002) and Greenberg (2008), is that PronZ sentences often have a 'hidden clause' reading of their subject (which these authors call 'denotation widening'), in which the predicate applies not to the nominal subject itself, but to an understood eventuality involving the subject. Thus, Heller and Greenberg note that the following example could mean not only that a VCR itself is expensive, but also that some contextually-relevant activity related to VCRs is expensive:

(9) video ze yakar.

VCR-M-S ZE-M-S expensive-M-S

'(Buying/maintaining/renting) a VCR is expensive.'

(Heller 1999)

The same point can perhaps be seen more clearly in example (10) below. Sentence (10) could mean that having signs in Hebrew, posting them, or some other contextually determined activity related to such signs is illogical; what this sentence cannot mean is that Hebrew signs themselves are illogical - a meaning which could only be achieved by using the agreeing copula PronH. 
(10) šlatim be- ivrit ze lo hegyoni.

signs-M-P in- Hebrew ZE-M-S not logical-M-S

'(Having/posting) signs in Hebrew is illogical.'

More generally, the fact that the predicate in a $z e$-clause does not apply to the literal denotation of the nominal subject itself is most clearly seen when the predicate is headed by an adjective that is ambiguous between an individual property reading and an eventive reading. In this case, only the latter reading is possible with PronZ, as illustrated below:

(11) zvuv ba-marak ze bari.

fly-M-S in-the-soup ZE-M-S healthy-M-S

'(Having) a fly in the soup is healthy (for the eater).'

(12) zvuv ba-marak hu bari.

fly-M-S in-the-soup PronH-M-s healthy-M-S

'A fly in the soup is healthy (= is in good health).'

Thus, while (12), with the agreeing PronH, means that the fly itself is healthy, (11) can only be understood as stating that having a fly in the soup is a healthy state of affairs, i.e., that it is healthy for whoever eats the soup. A possible explanation is suggested by Greenberg (2008) for similar cases: The individual property interpretation requires the predicate to apply to an animate entity, but (11) can only be interpreted with the 'semantic subject' being an eventuality. Other adjectives that give rise to similar effects include acuv 'sad', tov 'good', and nexmad 'nice'.

While the 'hidden eventuality' reading of $z e$-clauses is quite common, it is not the only kind of interpretation found with ze. The following examples illustrate what I refer to as a 'classification reading':

(13) ha-magavot ze ba-ambatya.

the-towels-F-P ZE-M-S in-the-bathroom

'The towels are (/should be) in the bathroom.'

(Greenberg 2008)

(14) tlunot ze tofes adom.

complaints-F-P ZE-M-S form-M-S red-M-S

'Complaints (should) involve a red form.'

In (13), from Greenberg (2008), the subject is claimed to somehow be associated with the locative predicate; the sentence does not entail that the towels are actually located in the bathroom in the real world. Sim- 
ilarly, in (14) the subject is classified as having something to do with a red form, where the exact relation is heavily context dependent. What is important is that these are not interpreted as predicational sentences, as they do not entail that the predicate actually applies to the subject. The fact that these examples seem to have a modal 'flavor' could possibly be the result of having to accommodate some kind of association between the subject and the post-copular phrase, where the use of ze apparently rules out a simple predication relation.

Like other types of copular clauses, $z e$-clauses often have generic subjects. Importantly, however, genericity in this case combines with the hidden eventuality or classification readings noted above. Thus, for instance, the predicate in (15) does not apply to the generic subject itself ('tigers') but to an understood eventuality, such as having tigers; this contrasts with the interpretation of (16), with the agreeing copula, in which the predicate is interpreted as a property of (generic) tigers themselves.

(15) nemerim (ba-bayit) ze nexmad.

tigers-M-P in-the-house ZE-M-S nice-M-S

'(Having/dealing with) tigers (at home) is nice.'

(16) nemerim hem nexmadim.

tigers-M-P PronH-M-P nice-M-P

'Tigers are nice.'

When the subject in a $z e$-clause is not a bare noun, another semantic peculiarity of this construction becomes visible. In the presence of a numeral, subjects of ze can only get a collective, non-specific reading (a similar observation, for Norwegian, is made in Hellan 1986, fn 20):

(17) šney orxim ze me'acben.

two guests-M-P ZE-M-S annoying-M-S

'(Having) two guests is annoying.'

(18) me'a kariyot ze kaved.

100 pillows-F-P ZE-M-S heavy-M-S

'100 pillows (together) is heavy.'

Thus, (17) cannot mean that there are two specific guests that are annoying, and (18) cannot mean that there are 100 heavy pillows; such readings are only possible with the agreeing copula PronH. 
While it might be tempting at this point to propose that ze-clauses can only have non-referential subjects, this is not the case. Specifically, as seen in (13) above or in the following two examples, it is possible to have definite subjects in a ze-clause, which would get either a hidden eventuality reading or a classification reading:

(19) ha-bibliyografya ze tov.

the-bibliography-F-S ZE-M-S good-M-S

'(Having/doing) the bibliography is good.'

(20) pariz ze be-carfat.

Paris-F-S ZE-M-S in-France

'Paris is/belongs in France.'

(Greenberg 2008)

Sentence (19) could be uttered when discussing what to do next when writing a paper; like in other hidden eventuality cases, it does not mean that the predicate ('good') describes a property of the subject itself (i.e., the sentence does not mean that the bibliography itself is good). Example (20), from Greenberg (2008), has a classification reading in which (the definite) 'Paris' is classified as belonging in France, which, as Greenberg notes, might be appropriate in a hypothetical scenario where cities have been moved around and have to be put back in place; or, perhaps more naturally, this sentence might be used in a geography teaching context where cities are matched to their corresponding country. It is thus clear that $z e$ sentences are not limited to non-specific or non-referential subjects.

To summarize the semantic facts so far, we note that typically, zeclauses do not express a predication relation between the subject and the post-copular phrase. The two common types of readings are either the hidden eventuality reading or the classification reading. These kinds of readings can be found with generic, non-specific indefinite, or with referential definite subjects.

It is beyond the scope of this paper to develop a formal semantic analysis of $z e$-clauses. We now return to the main goal of this paper, namely to the analysis of the underlying syntax that leads to non-agreement and to the observed semantics, where the main semantic characteristic that arises from the previous discussion is the lack of direct predication, i.e., the fact that in $z e$-clauses the predicate does not apply to the actual denotation of the overt subject. 


\section{Previous analyses}

While there has been a lot of interest in Hebrew copular clauses over the years, relatively little has been written about the syntax of non-agreeing $z e$. Thus, for instance, the influential work of Doron $(1983 ; 1986)$, who argues that PronH is an agreement clitic, offers no analysis for ze. Similarly, Sichel (1997), who proposes that the agreeing variety of PronZ is an instantiation of AgrO, mentions non-agreeing PronZ only in a footnote where it is dismissed as falling under a special class of 'metalinguistic expressions'. Works on the semantics of $z e$, noted already above, include Heller (1999; 2002) and Greenberg (2008), according to whom PronZ expresses identity (possibly via type-shifting). As to the syntactic aspects of the construction, Greenberg proposes that 'non-agreeing' PronZ actually involves agreement with a phonetically null noun inside the predicate, and hence the syntactic properties are essentially reduced to a stipulation that $z e$ agrees 'to the right'.

Below I discuss the possibility of explaining the facts discussed above by extending two previous syntactic analyses of related constructions. I argue that neither of these approaches provides a true solution for the puzzles raised by this construction.

\subsection{Against the ze-as-subject approach}

One objection that could be raised regarding the discussion so far is that it presupposes that $z e$ is a copula. If, alternatively, $z e$ were in fact a pronominal subject, rather than a copula, then much of the discussion so far would have been irrelevant. While, to the best of my knowledge, the hypothesis that $z e$ in sentences like those discussed above is not a copula has not been argued for, Hazout (1994) considers the status of ze that occurs with what might look like sentential subjects:

(21) lilmod sinit ze kaše.

learn-INF Chinese ZE-M-S difficult-M-S

'Learning Chinese is difficult.'

${ }^{3}$ Greenberg focuses on cases where the post-copular predicate is adjectival; her analysis leaves open the question of why ze only optionally agrees with a nominal predicate, as was shown in (6). 
Hazout argues that $z e$ in this case is not a copula but the subject, with the infinitival 'subject' being in fact an adjunct. Thus, for (21) Hazout argues for the following kind of structure:

(22) [IP [CPlilmod sinit] [IP ze kaše]]

Attempting to extend Hazout's (1994) proposal to instances of PronZ in what seems to be a copular clause with a nominal subject would mean that PronZ is not a copula but a pronominal subject, and that the 'subject' is a left-dislocated topic or some other left-adjoined element:

(23) $\mathrm{DP}_{i}\left[\mathrm{TP}_{\mathrm{ze}}\right.$ Pred $]$

In the context of the current discussion, this would have the advantage of providing a trivial explanation for what looks like lack of agreement, which would be analyzed as 3rd person singular agreement between the subject $z e$ and the predicate. There are, however, some significant problems with this approach.

The first problem is that $z e$ as a pronoun is usually restricted to non-human/inanimate referents:

(24) ha-iša ha-zot, hi / *ze bat me'a.

the-woman-F-S the-this-F-S she it 100 years old

'This woman, she's 100 years old?'

Therefore, if PronZ is simply the pronoun $z e$ which is coreferential with the preceding DP, the fact that it is used with subjects having human referents, as in $(25)$, is unexpected. ${ }^{4}$

(25) ha-iša ha-zot ze tofa'a.

the-woman-F-S the-this-F-S ZE-M-S phenomenon-F-S

'This woman is a phenomenon.'

While the discussion in the previous sections suggests that the clauseinitial DP in sentences of this kind receives an eventuality reading, which might make the use of an inanimate pronoun less surprising (if $z e$ was a pronoun and not a copula), this still begs the question of why left dislocation would have to lead to such an eventuality reading.

4 The generalization about the distribution of the pronoun $z e$, however, is more complicated than given in the brief discussion above; see for instance Sichel (2001) and Greenberg (2008). 
A second problem for the $z e$-as-subject approach is that it predicts a much wider distribution for ze than is actually attested. If $z e$ were simply the subject, which follows a left-dislocated topic, there would be no obvious reason why this would be limited to present tense clauses. In reality, however, sentences with $\mathrm{DP}+z e$ followed by a finite VP are only grammatical with the special intonation characteristic of left dislocation structures, which often involves a brief pause after the dislocated DP. Thus, with a "flat" intonation and no pause following the DP, the following are judged by most speakers as ungrammatical or highly marginal: ${ }^{5}$

(26) *yeladim ze itger ota.

children-M-P ZE-M-S challenged-M-S her

(Intended:) '(Having/dealing with) children challenged her.'

(27) *štey be'ayot ze matrid oti.

two problems-F-P ZE-M-S bothers-M-S me

(Intended:) 'Having two problems bothers me.'

Another argument against the $z e$-as-subject approach has to do with the fact that clauses involving topic left-dislocation (TLD) can be distinguished from $z e$-clauses not only prosodically but also in terms of word order. When applying wh-movement out of the predicate in a $z e$-clause, the fronted $w h$-phrase precedes the DP:

(28) nemerim ze mafxid me'od.

tigers-M-P ZE-M-S scary-M-S very

'Tigers are very scary.'

(29) ad kama $_{i}$ nemerim ze mafxid $t_{i}$ ?

to what extent tigers-M-P ZE-M-S scary-M-S

'To what extent are tigers scary?'

This contrasts with the order in real TLD constructions, where a fronted wh-phrase follows a topicalized DP:

${ }^{5}$ More generally, my claim is not that $z e$ is never a subject and always a copula, but simply that it has a copular use, which is subject to different constraints than the left-dislocation construction. 
(30) nemerim, ad kama $i$ ze mafxid $t_{i}$ ?

tigers-M-P to what extent ZE-M-S scary-M-S

'Tigers, to what extent is it scary?'

This essentially suggests that the linear order in a sentence like (28), as in most other examples discussed in this paper, is in fact ambiguous between a left-dislocation construction, with $z e$ as a subject, and a construction where $z e$ is a copula; prosody may sometimes serve a disambiguating function. A consequence of this ambiguity is that not all instances of $z e$ preceding verbless predicates can be reduced to subjects.

Finally, the $z e$-as-subject analysis cannot be extended to other languages in which similar phenomena are found; specifically, this kind of analysis is unavailable for Scandinavian 'pancake sentences' (Wechsler 2011), where non-agreeing copular clauses clearly do not involve anything that could be argued to be a pronominal subject: ${ }^{6}$

(31) Pannkak-or är gott.

pancakes-pl be-pres good-nt.sg

'Situations involving pancakes are good.' $\quad$ (Swedish; from Wechsler 2011)

Unlike in Hebrew, Scandinavian non-agreeing copular clauses involve the same copula as in agreeing clauses, as in (32):

(32) Pannkak-or är gul-a.

pancakes-pl be-pres yellow-pl

'Pancakes are yellow.'

(Swedish; from idem.)

As the copula in (31) is clearly not a pronominal element, it becomes much less appealing to analyze Hebrew ze as a pronoun in ze-clauses, as this kind of analysis would not apply crosslinguistically.

Thus, we conclude that PronZ sentences are not TLD sentences, and reject the ze-as-subject approach for copular clauses.

${ }^{6}$ As pointed out to me by an anonymous reviewer, it might be the case that Russian copular clauses with eto and Polish clauses with to could also be relevant here for a true crosslinguistic analysis. As it is not immediately clear to what extent the constraints on Hebrew ze match those for Russian and Polish eto/to, I leave it as an open question whether these Slavic copular constructions should really be subject to the same kind of analysis as that proposed here for Hebrew and Scandinavian copular clauses.

Acta Linguistica Hungarica 59, 2012 


\subsection{Against the hidden infinitive approach}

Another possible line of analysis that will be rejected is the hidden infinitive approach, explicitly proposed in some of the literature on Scandinavian non-agreeing subjects of copular clauses (see e.g., Josefsson 2009). The obvious motivation for this approach comes from the hidden eventuality interpretation discussed in section $\mathbf{2 . 2}$, where $z e$-clauses can be paraphrased using an overt infinitive. Hence a possible hypothesis is that the subject of $z e$ is actually an infinitival clause, with a phonetically null verb:

(33) $[\mathrm{TP}[\mathrm{CP} P$ DP] ze Pred]

Under this kind of analysis, the observed lack of agreement is simply default agreement, which is the typical kind of agreement observed with clausal subjects. Furthermore, the interpretation of the subject as denoting an eventuality requires no special explanation if the subject is in fact clausal.

One problem with adopting this kind of approach is that for $z e$ clauses that have the classification reading, a hidden infinitive analysis does not seem to be semantically motivated. Thus, for instance, the following examples have no reasonable paraphrase with an infinitival clause:

(34) pariz ze be-carfat.

Paris-F-S ZE-M-S in-France

'Paris is in France.'

(35) šmarim ze xaya.

yeast-M-P ZE-M-S animal-F-S

'Yeast are an animal.'

Therefore, this approach is not as attractive as it might seem at first due to the fact that it does not really offer a solution to the whole problem, only to certain sub-cases of it. Note that this shortcoming of the analysis is much harder to notice from a consideration of the Scandinavian languages for which it was proposed, as in these languages the only overt evidence for the non-agreeing status of the subject is that it does not trigger agreement on predicate adjectives, and hence clauses with non-adjectival predicates like those in (34)-(35) might not seem to require the same kind of analysis. 
A second argument against this approach, following a similar argument made by Hellan (1986), is that adding an overt nominalization to the post-copular predicate makes a paraphrase with an overt infinitive impossible; nevertheless, there is still no subject- $z e$ agreement:

(36) fizika ze kaše le-havana.

physics-F-S ZE-M-S hard-M-S to-understanding

'Physics is hard to understand.'

(37) nemalim ba-marak ze bari le-crixa yom-yomit.

ants-F-P in-the-soup ZE-M-S healthy-M-S to-consumption daily

'Ants in the soup are healthy for daily consumption.'

Therefore, it is not even true that all non-agreeing ze-clauses with a hidden eventuality interpretation can be reduced to a hidden infinitive.

Finally, as noted by Wechsler (2011), the hidden infinitive approach seems in essence to predict overt noun phrases, with eventive interpretations, to be possible wherever an infinitival clause is possible. The fact that this is not the case suggests that reducing non-agreeing subjects to hidden infinitives is not the right analysis.

In what follows, I will therefore adopt neither the hidden infinitive approach, nor the $z e$-as-subject approach. We thus still have to explain the lack of agreement, as well as the fact that ze clauses are interpreted as they are.

\section{The source of non-agreement}

Failure of a pair of elements to agree could follow from two types of reasons: either the two elements do not stand in the right structural configuration; or one (or both) lacks the features needed for agreement. In the case of $z e$, a simple structural account could provide a partial explanation based on standard Minimalist machinery: If we assumed that the subject in a $z e$-clause is generated in a position above $z e$ and above the predicate, then neither $z e$ nor the predicate could probe for the features of the subject and agree with it.

This, however, leaves several major issues open. Most importantly, it offers no explanation for the semantic effects associated with $z e$, and in some cases, such as the obligatory non-specific reading of subjects quantified by numerals, actually predicts the opposite of what is observed. 
As shown in (17)-(18) above, such subjects can only get a non-specific, narrow scope reading; but according to most approaches that tie scope to structural position, high positions correspond to wide scope and/or to specific readings (see e.g. Diesing 1992). Thus, the semantics of ze clauses does not simply follow from the hypothesis that these involve generating the subject in a high position.

A further problem, to be discussed below, is that simply assuming that subjects of $z e$ occupy a high structural position offers no explanation for other deficiencies displayed by such subjects. The alternative to be proposed below focuses on the feature deficiency of $z e$-subjects.

\subsection{Does the subject have features?}

In certain respects, the subject in a ze-clause looks as if it has no $\varphi$ features. Most obviously, the fact that it agrees neither with the copula nor with predicate adjectives would be trivially accounted for if the subject simply lacked agreement features. Somewhat more surprisingly, subjects of $z e$ also fail to participate in other operations that depend on having features - most notably, they cannot participate in binding relations. As illustrated in the following examples, attempting to bind either an anaphor or a pronoun by the subject of a $z e$-clause leads to ungrammaticality: ${ }^{7}$

${ }^{7}$ An anonymous reviewer has suggested that an anaphor can be bound by the subject of $z e$ if it denotes an abstract entity, and that in that case the anaphor must be masculine singular, as in the following example:

(i) nevu'a šxora ze midey pa'am magšim et acmo /*acma. prophecy.F-S black.F-S ZE-M-S sometimes realizes.M-S OM self-M-S self-F-S 'A bad phophecy sometimes materializes/realizes itself.'

Speakers' judgments on such sentences are somewhat mixed, and are even less clear when the semi-idiomatic anaphoric expression magšim et acmo ('realizes itself, materializes') is replaced by a fully compositional VP containing an anaphor. I therefore do not pursue the hypothesis that the ungrammaticality of examples (38)-(39) is conditioned by how abstract the subject is. Note further that even in examples like (i), the features of the anaphor cannot be determined by the morphosyntactic features of the subject's head noun but must be the default 3rd person singular, which lends further support to the claim that subjects of ze are somehow deficient in their features. 
(38) ${ }^{*}$ namer $_{i}$ ze mesukan le-acmo $i \quad / l_{i}$. tiger-M-S ZE-M-S dangerous-M-S to-self-M-S to-it-3M.S (Intended:) 'A tiger is dangerous to itself.'

(39) ${ }^{*}$ memšalot $_{i}$ ze mo‘il le-acman ${ }_{i} /$ la-hen $_{i}$. governments-F-P ZE-M-S beneficial-M-S to-self-F-P to-them-3F.P (Intended:) 'Governments are beneficial to themselves.'

Both of the above examples would be grammatical if the dative element was absent or not coreferential with the subject. Furthermore, the ungrammaticality in these cases contrasts sharply with the grammaticality of parallel sentences with the agreeing copula PronH, where anaphors in sentences similar to (38)-(39) can be bound by the subject (which also triggers agreement on the predicate adjective):

(40) namer $_{i}$ hu mesukan le-acmo $i$.

tiger-M-S PronH-M-S dangerous-M-S to-self-M-S

'A tiger is dangerous to itself.'

(41) memšalot $_{i}$ hen mo'ilot le-acman ${ }_{i}$. governments-F-P PronH-F-P beneficial-F-P to-self-F-P 'Governments are beneficial to themselves.'

While the ungrammaticality of a pronoun in (38)-(39) might simply follow from a Condition $\mathrm{B}$ violation (i.e., from the fact that the subject stands in a local c-command relation with the pronoun, which also accounts for the fact that the PronH counterpart of these sentences is also ungrammatical), the ungrammaticality of the anaphor is suprising. Under the assumption that binding requires identity of referential index, what these examples suggest is that the subject of $z e$ does not have the kind of index necessary for binding. Following the discussion of similar facts in Pereltsvaig (2006), I conclude that the subject of $z e$ does not have the full set of features that are typically found on referential nominals. We return to the specifics of this proposal in section $\mathbf{4 . 2}$ below.

Beyond nominal subjects, for which lack of agreement features is a somewhat exceptional property, ze-clauses also allow infinitival and PP subjects (Berman-Grosu 1976; Greenberg 2008), for which lack of features is perhaps the null hypothesis. Interestingly, such subjects are impossible with the agreeing copula PronH (as well as in clauses containing a finite VP): 
(42) lašir ba-miklaxat ze / $/$ hu $^{\text {hef. }}$ sing-INF in-the-shower ZE-M-S PronH-M-S fun 'Singing in the shower is fun.'

(43) ba-regel ze $\quad / *$ hu me'ayef. in-the-foot ZE-M-S PronH-M-S tiring-M-S 'By foot it's tiring.'

The conclusion so far is that subjects of $z e$-clauses are either featureless, or have features that are 'invisible' to the syntax. Yet this conclusion fails to account for the simple fact that from the point of view of DPinternal syntax, subjects of ze certainly do have features. In particular, such subjects show subject-internal concord with APs, as in (44); as well as subject-internal agreement with relative clauses, as illustrated in (45):

(44) yeladim ktanim ze avoda kaša.

children-M-P little-M-P ZE-M-S work-F-S hard-F-S

'Little children is hard work.'

(45) mexonit še-mitpareket pit'om ze me'acben.

car-F-S that-falls-apart-F-s suddenly ZE-M-S annoying-M-S

'(Having/dealing with) a car that suddenly falls apart is annoying.'

Thus, while the subject of ze-clauses looks featureless from the point of view of clausal syntax, DP-internally it clearly does have features. From a descriptive point of view, such a split is not unusual (see e.g. Corbett 2006); the theoretical question is how the 'partial featurelessness' of $z e$ subjects should be analyzed. Below I propose an analysis which adopts some aspects of previous analyses of 'hybrid agreement', such as the works of Wechsler-Zlatić (2003) and Pereltsvaig (2006); like these authors, I claim that a proper syntactic analysis of noun phrase syntax must involve a reconsideration of the traditional bundle of person, number and gender features.

\subsection{A two-tier analysis}

Two possible approaches might be proposed for representing the partial lack of features discussed above: one is to derive it from the structure of the noun phrase, and the other is to consider a more elaborate feature composition than a simple bundle of $\varphi$-features. 
Taking the structural approach, we may exploit the assumption that a DP consists of multiple layers (e.g., NP, NumP and DP), each (potentially) with its own set of features. Following the analysis in Danon (2011), we may assume that $\mathrm{N}$ and/or Num enter the derivation with valued gender and number, while $\mathrm{D}$ typically enters the derivation with unvalued gender and number (and valued person). Agreement between $\mathrm{D}$ and NP/NumP leads to the typical situation where DP carries a full set of $\varphi$-features, and hence is able to participate in 'external' Agree. ${ }^{8}$ In $z e$-clauses, however, we might propose that the $\mathrm{D}$ of the subject lacks these features, and it is thus 'invisible' to DP-external agreement. This analysis would therefore reduce the observed phenomenon to the presence of a 'defective' D head. Note that Hebrew is a language in which D has been argued to be an abstract head, rather than the locus of overt determiners or articles (see e.g. the discussion in Danon 2006); therefore, under this analysis there is no need to assume that lexical determiners are ambiguous in terms of their features, but simply that there is an optional abstract D that lacks agreement features.

An alternative analysis, which does not depend on the distribution of features among nominal functional projections, relies on the INDEX/CONCORD distinction often made in the HPSG literature (Kathol 1999; Wechsler-Zlatić 2003). According to this approach, NPs normally carry not one, but two, sets of agreement features: CONCORD features, which are used in NP-internal agreement; and INDEx features, which are used in NP-external agreement, binding, etc. This duality makes it possible to hypothesize that what makes non-agreeing subjects in $z e$-clauses special is that they have CONCORD but lack INDEX.

In fact, both of the approaches outlined above (as well as 'hybrid' approaches, along the lines of Pereltsvaig 2006) capture the same idea - that the subject of $z e$ is 'defective' in lacking one of the feature bundles that are typically found in a noun phrase. In what follows, I will use the term 'INDEX features' to refer to both implementations (i.e., both to HPSGstyle INDEX features and to features of D in the Minimalist/cartographic sense). The hypothesis is thus that subjects of ze lack INDEX features, under one of the implementations proposed above.

8 See the discussion in Danon (2011) for further issues regarding the model of Agree that is necessary for allowing the features on D to be available as goals. Specifically, adopting a feature-sharing approach to agreement following PesetskyTorrego (2007) allows for an analysis in which the features on D are not deleted after being valued via DP-internal agreement, and in which the interpretability of these features is independent of where they are initially valued.

Acta Linguistica Hungarica 59, 2012 


\subsection{Lack of index: semantic consequences}

Lack of INDEX features has two kinds of effects. At a purely syntactic level, no external agreement and no binding are possible with a DP that lacks these features, as discussed in the previous sections. But this lack of features has semantic consequences as well: as INDEX features serve as argument identifiers, in their absence there is no formal encoding of the subject as being an argument. Under the featureless-DP implementation, this fits directly into the long tradition of identifying the DP layer with argumenthood; see e.g. Chierchia (1998); Longobardi (1994); Pereltsvaig (2007); Progovac (1998) and many others. What this means is that the subject of a ze-clause must be interpreted non-argumentally (see also Pereltsvaig 2006, who similarly claims that non-agreeing subjects in Russian and Norwegian are non-referential). ${ }^{9}$ The exact details at a formal level are quite theory-dependent, and it is beyond the scope of this paper to develop a full formal analysis. One possible approach, which is discussed below, is that such subjects are not interpreted as generalized quantifiers, and hence their semantic relation to the predicate cannot be the same as that of subjects that are GQs (Barwise-Cooper 1981; Keenan 1987). In what follows, I briefly consider the semantic consequences of analyzing $z e$-subjects as predicates.

One fact that immediately falls out of this hypothesis is the obligatory non-specific, collective, reading of plural indefinite subjects of $z e$, repeated in the example below:

(46) me'a kariyot ze kaved.

100 pillows-F-P ZE-M-S heavy-M-S

'100 pillows (together) is heavy.'

In this case, the lack of a distributive, quantificational, reading can be accounted for by assuming that the sentence is interpreted as expressing a subset relation between two predicates; roughly, this can be paraphrased as 'The set of entities having the property of being pillows and having cardinality of 100 is a subset of heavy entities.' ${ }^{, 10}$

${ }^{9}$ Pereltsvaig, however, explicitly argues that such subjects are argumental from a thematic point of view.

${ }^{10}$ As pointed out to me by Arik Cohen (p.c.), it might be more accurate to characterize the interpretation in such cases in a manner similar to that of generic sentences, i.e., as expressing a non-accidental relation between two predicates 
Furthermore, this analysis predicts that truly quantificational subjects, which cannot be interpreted as predicates, would be ungrammatical with ze. Indeed, replacing the subject in (46) with a quantificational DP as in (47) leads to ungrammaticality:

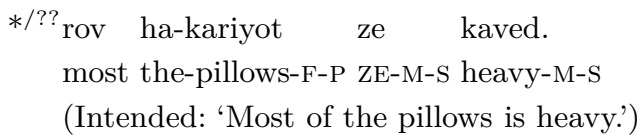

This is explained by the fact that, unlike the subject in (46), the subject in (47) cannot receive an interpretation at the type of predicates.

For some speakers, however, (47) is not entirely ungrammatical, and is marginally acceptable under a hidden eventuality reading, such as 'Lifting most of the pillows is heavy'; the fact that this is only marginal might be attributed to fact that a predicate like 'heavy' is not normally applicable to events. Other ze-clauses with quantificational subjects, but with predicates that can more naturally apply to events, are judged as somewhat better:

(48) 'xeci me-ha-orxim ze me'acben.

half of-the-guests ZE-M-S annoying-M-S

'(Having) half of the guests is annoying.'

Just as in the previous example, this is ungrammatical with a reading where the predicate applies to the quantified subject, but is (somewhat marginally) acceptable if it can be supplied with a contextually relevant hidden eventuality reading. This raises the question of how the hidden eventuality reading is derived, under the assumption that the subject is not grammatically marked as being argumental. I propose to adopt an aspect of the analysis of Greenberg (2008), who argues that the hidden eventuality reading ('denotation widening' in her terms) is the result of shifting the denotation of the subject to a contextually-determined property $\mathrm{P}$ related to the overt nominal. Consider for instance the following example:

that nevertheless allows for exceptions, rather than as universal quantification as implied by the subset relation. The question that this raises is how ze sentences with bare plural subjects differ from generic sentences involving the agreeing copula PronH. I leave this as an open question.

Acta Linguistica Hungarica 59, 2012 
(49) knasim ze metišs.

conferences-M-P ZE-M-S exhausting-M-S

'(Going to/attending) conferences is exhausting.'

Under the proposed analysis, the denotation of the generic 'conferences' is shifted to a contextually-determined property $\mathrm{P}$ related to conferences, e.g., the property of attending conferences. Subsequently, we may assume the same semantic relation between the subject and the post-copular predicate as that proposed for cases like (46) above - namely, predicate entailment/subset, which would result in the reading 'The set of entities having the property $\mathrm{P}$ is a subset of the set of exhausting things.'

In the case of a quantified subject, as in (47) or (48) above, the same analysis would apply, by shifting the literal denotation of the (quantified) subject to a contextually-determined predicate related to such quantified nominals. We thus end up with the prediction that quantified subjects of $z e$ would be possible, but highly sensitive to the availability of a contextually relevant property of events related to such quantified nominals. Indeed it seems that speakers' judgments for such sentences improve once a suitable context is provided.

While the above is far from being a complete formal semantic analysis of the ze construction, the main characteristic of the proposal is that, while it is motivated by syntactic considerations of agreement patterns, it also correctly predicts the lack of an argument-predicate relation in ze clauses and the lack of certain readings of quantified ze-subjects. As such, this kind of analysis seems to have an advantage over a purely syntactic analysis of $z e$-clauses, like the analyses discussed in section $\mathbf{2}$.

\subsection{The features of $z e$}

The hypothesis raised in the previous sections is that the subject in a $z e$-clause lacks INDEX features. Given that this already makes subject agreement impossible, the question is whether there is any reason to assume that the copula has agreement features. The two answers that should be considered are that either the copula too lacks features, or that it has features that receive default values.

Under standard Minimalist assumptions, the former answer seems to require no extra stipulations. If $z e$ entered the derivation with unvalued $\varphi$-features, and neither the subject nor the predicate had valued ones, the prediction is that the derivation would crash. Therefore, if the 
subject lacks features, selecting a copula that also lacks features leads straightforwardly to a convergent derivation. Under this analysis, $z e$ is characterized as being lexically featureless, and its co-occurrence with featureless subjects is an indirect consequence of the need to value any (uninterpretable) features that a copula might enter the derivation with.

The alternative analysis, according to which $z e$ enters the derivation with unvalued features and values them as default, raises the question of how such default valuation applies in the grammar; I will therefore not pursue this line of analysis. However, as the status of default agreement is a more general issue in Minimalist syntax, it might be that there is a way to accommodate the $z e$-with-defaults approach as part of a broader analysis of defaults.

I thus conclude that in the non-agreeing case, both the subject and ze lack agreement features. The subject enters the derivation with no INDEX features and cannot act as a goal (even if there was a probe). ze lacks $\varphi$-features and does not act as a probe. There is no need to stipulate any construction specific rule that would ensure that both the subject and $z e$ lack features at the same time, as the lack of features on the latter is forced by the lack of suitable goal to agree with.

\section{Conclusions}

Syntactic considerations lead us to conclude that lack of agreement in $z e$-clauses follows from lack of agreement features on the subject. The missing features are distinct from the features used in DP-internal agreement, thus supporting a more elaborate view of nominal features than in the simple view commonly assumed, of a single bundle of $\varphi$-features.

Lack of features on the subject has been argued to trigger 'opaque' interpretations where the subject receives a non-argumental interpretation. Thus, the proposed analysis is supported not only by syntactic agreement facts but also by considerations of the syntax-semantics interface. The ze construction hence provides further empirical evidence for the hypothesis that argumenthood is encoded syntactically by functional elements-either by features of DP or by a set of features that is distinct from the features expressed morphologically on the noun.

Looking at the broader theoretical consequences, the analysis proposed in this paper is compatible with the standard view in much of the current syntactic literature, according to which (dis-)agreement itself is governed by purely morphosyntactic factors - namely, the presence 
or absence of features and the hierarchical configuration in which they appear; once these have been determined, agreement operates 'mechanically' with no sensitivity to semantic factors. In this model, semantic effects that correlate with copula agreement (or the lack of it) have been argued to be tied to the presence or absence of interpretable features of the DP, on which agreement also depends. The relation between agreement and interpretation is hence an indirect one, in which each of these is independently sensitive to the same formal factor.

\section{References}

Barwise, Jon-Robin Cooper 1981. Generalized quantifiers and natural language. In: Linguistics and Philosophy 4:159-219.

Berman, Ruth Aronson-Alexander Grosu 1976. Aspects of the copula in Modern Hebrew. In: Peter Cole (ed.): Studies in Modern Hebrew syntax and semantics, 265-85. North Holland, Amsterdam.

Bobaljik, Jonathan David 2008. Where's Phi? Agreement as a postsyntactic operation. In: Daniel Harbour-David Adger-Susana Béjar (eds): Phi theory: Phi-features across modules and interfaces, 295-328. Oxford University Press, Oxford.

Chierchia, Gennaro 1998. Reference to kinds across languages. In: Natural Language Semantics $6: 339-405$.

Chomsky, Noam 2000. Minimalist inquiries: The framework. In: Roger Martin-David Michaels - Juan Uriagereka (eds): Step by step: Essays on minimalist syntax in honor of Howard Lasnik, 89-155. MIT Press, Cambridge MA.

Chomsky, Noam 2001. Derivation by phase. In: Michael Kenstowicz (ed.): Ken Hale: A life in language, 1-52. MIT Press, Cambridge MA.

Corbett, Greville G. 2006. Agreement. Cambridge University Press, Cambridge.

Danon, Gabi 2006. Caseless nominals and the projection of DP. In: Natural Language \& Linguistic Theory 24:977-1008.

Danon, Gabi 2011. Agreement and DP-internal feature distribution. In: Syntax 14: 297-317.

Diesing, Molly 1992. Indefinites. MIT Press, Cambridge MA.

Doron, Edit 1983. Verbless predicates in Hebrew. Doctoral dissertation, University of Texas at Austin.

Doron, Edit 1986. The pronominal "copula" as agreement clitic. In: Hagit Borer (ed.): Syntax and semantics 19: The syntax of pronominal clitics, volume 19, 313-32. Academic Press, Orlando.

Greenberg, Yael 2008. Predication and equation in Hebrew (nonpseudocleft) copular sentences. In: Sharon Armon-Lotem-Gabi Danon-Susan Rothstein (eds): Current issues in generative Hebrew linguistics, 161-96. John Benjamins, Amsterdam \& Philadelphia. 
Hazout, Ilan 1994. The Hebrew pronoun ze and the syntax of sentential subjects. In: Lingua $93: 265-82$.

Hellan, Lars 1986. The headedness of NPs in Norwegian. In: Pieter Muysken-Henk van Riemsdijk (eds): Features and projections, 89-122. Foris.

Heller, Daphna 1999. The syntax and semantics of specificational pseudoclefts in Hebrew. Master's thesis, Tel Aviv University.

Heller, Daphna 2002. On the relation of connectivity and specificational pseudoclefts. In: Natural Language Semantics $10: 243-84$.

Josefsson, Gunlög 2009. Peas and pancakes: On apparent disagreement and (null) light verbs in Swedish. In: Nordic Journal of Linguistics $32: 35-72$.

Kathol, Andreas 1999. Agreement and the syntax-morphology interface in HPSG. In: Robert D. Levine-Georgia M. Green (eds): Studies in contemporary phrase structure grammar, 223-74. Cambridge University Press, Cambridge.

Keenan, Edward 1987. A semantic definition of "indefinite NP". In: Eric Reuland - Alice ter Meulen (eds): The representation of (in)definiteness, 286-317. MIT Press, Cambridge MA.

Longobardi, Giuseppe 1994. Reference and proper names: A theory of N-movement in syntax and Logical Form. In: Linguistic Inquiry $25: 609-65$.

Pereltsvaig, Asya 2006. Small nominals. In: Natural Language \& Linguistic Theory 24 : 433-500.

Pereltsvaig, Asya 2007. Copular sentences in Russian. Springer, Dordrecht.

Pesetsky, David - Esther Torrego 2007. The syntax of valuation and the interpretability of features. In: Simin Karimi-Vida Samiian-Wendy K. Wilkins (eds): Phrasal and clausal architecture. Syntactic derivation and interpretation, 262-94. John Benjamins, Amsterdam \& Philadelphia.

Progovac, Ljiljana 1998. Determiner phrase in a language without determiners. In: Journal of Linguistics $34: 165-79$.

Sichel, Ivy 1997. Two pronominal copulas and the syntax of Hebrew nonverbal sentences. In: Ralph Blight-Michelle Moosally (eds): Texas Linguistic Forum 38: The syntax and semantics of predication, 295-306. University of Texas Department of Linguistics, Austin, Texas.

Sichel, Ivy 2001. The syntax of pronouns and features. Doctoral dissertation, City University of New York.

Wechsler, Stephen 2011. The structure of Swedish pancakes. Paper presented at CSSP 2011, Université Paris 8. (http://tinyurl.com/784od4w)

Wechsler, Stephen-Larisa Zlatić 2003. The many faces of agreement. CSLI Publications, Stanford. 